\title{
NUEVAS APORTACIONES A LA VIDA Y OBRA DEL PINTOR JOSÉ MARÍA ROMERO (1816-1894)
}

\section{NEW CONTRIBUTIONS ON THE LIFE AND WORK OF THE PAINTER JOSÉ MARÍA ROMERO (1816-1894)}

\author{
Álvaro Cabezas García \\ Grupo de investigación HUM-317: Laraña \\ alvarocabezasgarcia@gmail.com \\ María Josefa Carro Valdés-Hevia \\ mariacarrovaldes1@gmail.com
}

En el presente estudio se aportan datos hasta ahora desconocidos sobre la biografía del pintor romántico sevillano José María Romero, entre los que destacan las fechas de nacimiento y fallecimiento, así como otros aspectos relativos a su familia y trayectoria artística en Sevilla, Cádiz y Madrid. Además, se añaden siete pinturas inéditas a su catálogo artístico localizadas en la Casa Generalicia de la orden de Franciscanas del Rebaño de María de la ciudad de Cádiz.

Palabras clave: José María Romero; pintura; Romanticismo; género religioso; Cádiz.

The present paper provides unknown information on the Romantic and Sevillian painter José María Romero biography, for example dates of birth and death and aspects related to family life and artistic career in Seville, Cádiz or Madrid are prominent among others. In addition, seven new paintings are added to his artistic catalogue. These unique pieces have been localized in the Casa Generalicia of the Franciscan Order of Rebaño de María in Cádiz.

Keywords: José María Romero; painting; Romanticism; religious genre; Cádiz. 


\section{INTRODUCCIÓN}

José María Romero fue "una de las personalidades más interesantes en el panorama del arte sevillano del siglo XIX"1. Por esa razón ha sido estudiado por los profesores Valdivieso y Fernández López en varias ocasiones². Como resultado, el catálogo de este pintor reúne en la actualidad unas setenta obras que han sido clasificadas en función de temáticas diversas entre las que destacan, por importancia, las del retrato, la pintura de Historia, el asunto religioso y el costumbrismo.

Posiblemente, las primeras referencias sobre su vida y obra sean las de Ossorio y Bernard que, entre sus principales características, señala que era "autor de gran número de copias muy elogiadas [...] de Murillo"'3. Esta práctica encontraba plena lógica y vigencia en el contexto histórico de su formación en el seno de la Escuela de Bellas Artes de Sevilla, institución derivada de la Real Escuela de las Tres Nobles Artes, nacida en el siglo XVIII gracias a la dirección de Francisco Bruna y Ahumada (Granada, 1719-Sevilla, 1807) y al tesón de un grupo de pintores herederos del taller de Domingo Martínez ${ }^{4}$. Precisamente en la Escuela de Bellas Artes hispalense ocupó Romero el cargo de ayudante de Pintura desde enero de 1844 y profesor encargado de la clase de Trozos desde noviembre de 1848, tras errar el tiro en su intención de hacerse cargo de la de Dibujo justo un año antes ${ }^{5}$. Tras los cambios sufridos por esta institución a partir de la Real Orden de 3 de

${ }^{1}$ FERNÁNDEZ LÓPEZ, José: "El asunto religioso en la obra del pintor romántico sevillano José María Romero", Laboratorio de Arte, 3, 1990, p. 199.

2 VALDIVIESO, Enrique: Pintura sevillana del siglo XIX. Sevilla, 1981, pp. 65-70; VALDIVIESO, Enrique: Historia de la pintura sevillana. Siglos XIII al XX. Sevilla, 1986 (2002), pp. 406-409; VALDIVIESO, Enrique: La pintura en el Museo de Bellas Artes de Sevilla. Sevilla, 1993, pp. 352 y 353; VALDIVIESO, Enrique: Catálogo de la colección de Mariano Bellver. Sevilla, 2010, pp. 534-542; y VALDIVIESO, Enrique y FERNÁNDEZ LÓPEZ, José: Pintura romántica sevillana. Sevilla, 2011, pp. 176-183.

${ }^{3}$ OSSORIO Y BERNARD, Manuel: Galería biográfica de artistas españoles del siglo XIX. Madrid, 1883-1884, pp. 595 y 596. Esta circunstancia y lo esmerado de su estilo provocaron que fuera con frecuencia considerado "el Murillo del siglo XIX".

${ }^{4}$ CABEZAS GARCÍA, Álvaro: Teoría del gusto y práctica de la pintura en Sevilla (1749-1835). Sevilla, 2015, pp. 189-256. Esta institución se consideró desde su origen continuadora de aquella Academia que había regentado, entre otros, Bartolomé Esteban $\mathrm{Mu}$ rillo en la Lonja hispalense durante algunos años del siglo XVII. Vid. GARCÍA BAEZA, Antonio: Entre el obrador y la academia. La enseñanza de las artes en Sevilla durante la segunda mitad del Seiscientos. Sevilla, 2014, p. 203.

5 Además, Romero formó parte, desde octubre de 1845, de la sección de pintura de la comisión formada para dictaminar sobre el monumento dedicado al arquitecto Juan de Herrera. Vid. MURO OREJÓN, Antonio: Apuntes para la historia de la Academia de Bellas Artes de Sevilla. Sevilla, 1961, pp. 49, 51 y 60. 
octubre de 1850, nuestro artista fue nombrado académico de la Real de Bellas Artes de Sevilla ${ }^{6}$.

El disfrutar de esta posición oficial le valió para convertirse -gracias a la rapidez con la que despachaba los encargos y a la solvencia técnica que mostraba al ejecutarlos-, en retratista de la Sevilla oficial. Quizá, por su carácter de testimonio de un acontecimiento histórico, sus piezas más logradas y monumentales sean El bautizo de la infanta doña María Isabel, condesa de París (1848, conservada en una colección particular de Villamanrique de la Condesa), Don Alfonso XII firmando el acta de colocación de la primera piedra del monumento a San Fernando y Don Alfonso XII contemplando en la Capilla Real de la Catedral de Sevilla el cuerpo incorrupto de San Fernando (1867, Ayuntamiento de Sevilla) ${ }^{7}$. Durante una quincena larga de años, Romero retrató a la mayoría de los integrantes de las más conspicuas familias sevillanas -impulsado, sobre todo, por su cercanía con los Montpensier, el conde de Ibarra y otros personajes como Tomás Murrieta, Fermín y Gabriel de la Puente y Mariano Artacoz ${ }^{8}$, alcanzando destacada excelencia en la plasmación de los niños como demuestra, por ejemplo, el Retrato de los hijos del conde de Ybarra (1852, colección particular sevillana) ${ }^{9}$. En ocasiones como esta conseguía el pintor despegarse del rígido modelo que utilizaba para el retrato de los mayores y explorar aspectos llenos de creatividad y delicadeza. Aunque con mucha menos frecuencia, José María Romero ensayó escenas costumbristas que lograban, con notorio refinamiento, unir el sabor de las fiestas y atuendos tradicionales con la exquisita galantería de interior ${ }^{10}$. Por último, fue en el género religioso donde, parece, tuvo menor predicamento -a tenor del escaso número de obras conservadas y de las críticas recibidas en la época-, pero este extremo de su producción se encuentra cada vez más y mejor estudiado ${ }^{11}$. Aunque siempre tomó como referencia el modelo murillista, hay que reconocer que algunas de sus composiciones obtienen altas cotas de espíritu clarividente, bien por el tema representado -Murillo mostrando su lienzo de la Inmaculada, conservada

${ }^{6}$ Ibidem, p. 71. En esa ocasión la institución pasó de trece a veinticuatro académicos.

${ }^{7}$ FERNÁNDEZ LÓPEZ, José: La pintura de Historia en Sevilla en el siglo XIX. Sevi1la, 1985, pp. 74 y 75. La identificación de los ciento cinco personajes representados en la primera de las obras fue dada a conocer por VALDIVIESO, Enrique: Pintura sevillana..., op. cit., pp. 66-67.

${ }^{8}$ GALÁN, Eva V.: Pintores del romanticismo andaluz. Granada, 1994, pp. 100-101.

9 Reproducido en VALDIVIESO, Enrique y FERNÁNDEZ LÓPEZ, José: Pintura romántica sevillana..., op. cit., p. 178.

${ }^{10}$ Esto se pone especialmente de manifiesto en el lienzo Baile en un interior burgués, de colección particular sevillana y reproducido en VALDIVIESO, Enrique: Historia de la pintura..., op. cit., p. 408.

${ }^{11}$ FERNÁNDEZ LÓPEZ, José: "El asunto religioso...", op. cit.; y VALDIVIESO, Enrique y FERNÁNDEZ LÓPEZ, José: Pintura romántica sevillana..., op. cit., pp. 182-183. 
en el Museo de Bellas Artes de Sevilla ${ }^{12}$, o por la factura empleada a la hora de componerlas: El sueño de San Martín, de colección particular sevillana, o La última comunión de la Magdalena, realizada en 1858, hoy depositada en el Museo Nacional de Bellas Artes de La Habana.

José María Romero ocupó en Sevilla, con su estilo frío y académico en los retratos, pero de marcadas formas románticas en otros géneros, la laguna estética dejada tras la marcha de Antonio María Esquivel (Sevilla, 1806-Madrid, 1857) y José Gutiérrez de la Vega (Sevilla, 1791-Madrid, 1865) a la capital de España a partir de 1841 y 1847, respectivamente, años en los que, con carácter definitivo, estos dos pintores asumieron distinciones y cargos de relieve tras largas temporadas de asiduidad en los círculos artísticos de la corte ${ }^{13}$. Desde finales de los años cuarenta hasta el curso 1866-1867 en que Romero trasladó sus actividades a Cádiz, la pintura hispalense representativa estuvo animada por la llama constante de su personalidad. A pesar de ello hasta el momento no se conocían los datos básicos sobre su vida y fallecimiento ${ }^{14}$, contexto y relaciones familiares, actividades conducentes a su formación, las circunstancias que vivió fuera de Sevilla y la trascendencia en forma de discípulos y seguidores que tuvo su obra artística. A continuación nos proponemos dar respuesta a algunas de estas cuestiones.

\section{APORTACIONES BIOGRÁFICAS}

La incógnita de la fecha de nacimiento queda resuelta gracias a la información suministrada por su partida de bautismo. Vino al mundo en Sevilla el 12 de mayo de 1816, bautizándose el 14 del mismo mes en la parroquia de Omnium Sanctorum como José María de Gracia. Sus padres fueron Manuel Romero y Gertrudis López, y actuaron como padrinos su tía materna María de Todos los Santos López y el esposo de esta, Salvador Gutiérrez ${ }^{15}$. Permaneció radicado en su collación natal hasta 1835, momento en que se convirtió en parroquiano del Salvador hasta 1839, según se desprende de su partida matrimonial ${ }^{16}$.

${ }^{12}$ La acertada atribución fue de VALDIVIESO, Enrique: La pintura..., op. cit., p. 352.

${ }^{13}$ VALDIVIESO, Enrique: Pintura sevillana ..., op. cit., pp. 35 y 43.

14 VALDIVIESO, Enrique y FERNÁNDEZ LÓPEZ, José: Pintura romántica sevillana..., op. cit., p. 176, proponían hacia 1815 y hacia 1883 para su nacimiento y óbito, respectivamente.

15 APOSS (Archivo de la Parroquia de Omnium Sanctorum de Sevilla), sección Bautismos, Libro de bautismos, $\mathrm{n}^{\circ}$ 25, 14-5-1816, f. 230.

${ }^{16}$ AGAS (Archivo General del Arzobispado de Sevilla), fondo Arzobispal. I, Vicaría. 1, Expedientes matrimoniales. 3, Expedientes matrimoniales secretos, 29-7-1841. Quizá por las características de la collación y de lo escueto de su partida de bautismo pueda presuponérsele un origen familiar humilde. 
En 1838 aparece inscrito como socio de la Real Sociedad Económica Sevillana de Amigos del País. Fue en la junta pública de 30 de mayo de ese año cuando fue inscrito sin tener que abonar ninguna cuota en metálico, ya que esta fue canjeada por la copia que Romero realizó de La coronación de los Ebrios por Baco (sic) de Velázquez, ventaja que también se permitió a pintores coetáneos como Manuel Barrón y Carrillo (Sevilla, 1814-1884) y Joaquín Domínguez Bécquer (Sevilla, 1817-1879). Ese mismo mes recibió Romero premio de carta de aprecio y permiso para rotular el llamador de su taller con la inscripción "premiado por la Sociedad Económica" como consecuencia de los trabajos de ebanistería que había emprendido ${ }^{17}$.

La partida de matrimonio ofrece varias noticias interesantes. En primer lugar, que antes de su casamiento había viajado a Cádiz y a Madrid, volviendo a Sevilla con cinco meses de anticipación a su enlace. Por ello podríamos preguntarnos si Romero fue a la corte -dominada en ese momento por el arte de los hermanos Madrazo-, para formarse o para tomar contacto con otros pintores, como los sevillanos Esquivel y Gutiérrez de la Vega, artistas con los que la obra de Romero muestra deudas estéticas y concepciones similares ${ }^{18}$. En segundo lugar, que contrajo matrimonio el 31 de julio de 1841 con Manuela Verdeja Lastra (Sevilla, 12 de enero de 1818-7 de octubre de 1862), quien fallecería prematuramente a causa de un derrame cerebral ${ }^{19}$. Era vecina de la collación del Salvador ${ }^{20}$, pero había vivido en la de San Pedro entre 1838 y 1840. Uno de sus cinco hermanos recibía el nombre de Ignacio - había nacido en julio de 1820 - y se dedicaba a la pintura. José María y Manuela se casaron en secreto para no tener gastos de mayor consideración y los testigos de boda fueron Manuel Moreno y Gabriel Robe1ledo. De este enlace germinaron dos hijas: María Encarnación, nacida el 24 de mayo de 1844 y bautizada en la parroquia del Sagrario el día 26 ${ }^{21}$, y María Dolores, nacida el 10 de septiembre de 1846 y bautizada en la misma parroquia el día

${ }_{17}$ Estas referencias documentales han sido extraídas del ARSESAP (Archivo de la Real Sociedad Económica Sevillana de Amigos del País), Libro de actas, nº 7, 1816-1854, 30-5-1838, p. 153.

${ }^{18}$ Sobre esta primera incursión madrileña se tiene constancia de la participación de Romero, en 1840, en la exposición organizada por la Academia de San Fernando con los cuadros El retrato de un sacerdote y Mancebo tapando los ojos a una joven. Vid. ARABASF (Archivo de la Real Academia de Bellas Artes de San Fernando), leg. 5-164-3, Comisión Central de Monumentos, Comisiones provinciales de monumentos, Sevilla, 1845-1846, 31 $12-1845$

19 APSS (Archivo de la Parroquia del Sagrario de Sevilla), sección Defunciones, $\mathrm{Li}$ bro de defunciones, $\mathrm{n}^{\circ} 34,7-10-1862$, f. 492. Hubo veinticuatro sacerdotes en el entierro, hecho que nos lleva a pensar que el matrimonio tenía posibilidades económicas en esos años.

20 AGAS, fondo Parroquia del Divino Salvador de Sevilla. sección I. Administración de sacramentos. 1. Bautismos, Libro de bautismos, nº 36, 14-1-1818, f. $20 \mathrm{v}$.

${ }^{21}$ APSS, sección Bautismos, Libro de bautismo, nº 80, 26-5-1844, f. 84v. 
$13^{22}$. Esta última profesó en 1883 en el convento de Santa María de Jesús, de clarisas franciscanas, y murió allí en $1910^{23}$. El primer domicilio que tuvo el matrimonio se ubicó en la calle Harinas $n^{\circ} 23$. El segundo, entre 1853 y 1864, en una casa con taller en Amor de Dios $n^{\circ} 3^{24}$.

El 4 de junio de 1843, cuando ya era profesor de la Escuela de Dibujo local, fue nombrado académico de mérito de la Sociedad Económica Sevillana de Amigos del País en agradecimiento a sus cuatro retratos de medio cuerpo ${ }^{25}$. Años más tarde, en 1847, y en esta ocasión en el seno de la Escuela de Bellas Artes, Romero intentó renunciar a los cargos que, junto con Barrón, había asumido en 1844. Se discutió la cuestión - probablemente se trataba de un asunto económico- y, finalmente, la Escuela no aceptó sus renuncias porque necesitaba estos efectivos para el normal desarrollo de la docencia ${ }^{26}$. Ese mismo año, junto con Joaquín Domínguez Bécquer, José María Escacena (Sevilla, 1800-1858) y José Roldán (Sevilla, 1808-1871), fue designado como aspirante para profesor de pintura de estudios superiores de la institución ${ }^{27}$.

Otro detalle que no se conocía de su trayectoria artística es el hecho de que fuera nombrado en 1850 -el mismo año en que se convirtió en académico- pintor de cámara de Isabel II. Así lo expresa el diario El Porvenir: "Con satisfacción hemos sabido que Su Majestad ha concedido el honor de Pintor de Cámara al aventajado joven don José María Romero. Justo es que se premie el talento de nuestros artistas que, en alguna manera, siguen las huellas del inmortal Murillo; el señor Romero es uno de aquellos artistas en quien puede recaer mejor el premio que se concede al hombre estudioso. Sus obras, tales como las que representa el Acta Bautismal de la señora Infanta Doña María Isabel Francisca de Asís, y otros que ha hecho en la Corte, son la mejor prueba de los adelantos de este notable

${ }^{22}$ Ibidem, 13-9-1846, f. 308v.

${ }^{23}$ Este detalle se conoce gracias a que sobre un cuadro de dicho convento reza la inscripción "En recuerdo del padre de la madre San Francisco Javier, que él lo pintó". VALDIVIESO, Enrique y MORALES, Alfredo J.: Sevilla oculta: monasterios y conventos de clausura. Sevilla, 1980, p. 171.

${ }^{24}$ MORILlA Y ALONSO, V.: Guía general de Sevilla y su provincia. Sevilla, 1860, p. 267.

25 ARSESAP, Libro de actas, 1817-1824, no 8, 4-6-1843, p. 153. Fue designado también para proporcionar una copia de un retrato de Isabel II al señor Illanes, que se iba a ocupar personalmente de ese cometido, pero necesitaba un original que, finalmente, le procuró Romero, que formaba parte de la comisión de ese asunto junto con Villanueva y Bejarano.

${ }^{26}$ ARABASIHS (Archivo de la Real Academia de Bellas Artes de Santa Isabel de Hungría de Sevilla), fondo Actas, Libro de actas, 1845-1852, s. f.

27 Ibidem. 
profesor. Felicitamos sinceramente al señor Romero por la distinción que acaba de merecer" 28 .

Aunque se conocía la fecha en que marchó a Cádiz, no se habían reseñado hasta ahora las circunstancias que su partida provocaron en la institución académica de Sevilla. Su sustituto salió de una terna de candidatos: Manuel Cabral Aguado-Bejarano (Sevilla, 1827-1891), Manuel Freyre y Reinoso y Francisco de Paula Escribano (Sevilla, 1820-1900). Finalmente fue el primero de ellos el ganador $^{29}$. A partir de entonces, Romero fue considerado académico supernumerario, con lo que hubo de devolver la medalla de oro que poseía, ya que la institución solo la reservaba para los numerarios ${ }^{30}$.

Su asentamiento en Cádiz se concretó de la siguiente manera: el 10 de julio de 1866 fue propuesto académico por pintura de la Academia, gracias al impulso de Adolfo de Castro (Cádiz, 1823-1898), Rafael Rocafoult y Eduardo J. de Montalvo, quienes pretendían que Romero ocupase la plaza de un académico recientemente fallecido, Gutiérrez y Montano ${ }^{31}$. En agosto fue recibido en esa corporación oficio del pintor agradeciendo el nombramiento. Ocupó el sillón XVII, que estaba dedicado a la plaza de teniente director de Pintura ${ }^{32}$ y tomó posesión de su cargo en febrero de $1867^{33}$.

Determinadas noticias extractadas de estudios generales indican que en la década de los setenta, con sus hijas ya crecidas y estando viudo, se mantuvo activo e itinerante entre Madrid -donde se le localiza en 1874-, Sevilla -donde realiza los retratos de Alfonso XII en 1877- y Cádiz, donde realiza las que quizá fueron sus últimas obras: las pinturas Sacra Familia, San Antonio y Dolorosa para la exposición de 1879 de aquella ciudad ${ }^{34}$. Hasta el momento, las fechas más tardías que se tenían sobre su vida eran 1882 y 1883. En el primer año la Guía de Gómez-Zarzuela situaba su domicilio sevillano en la calle de la Unión $n^{\circ}$ 9, actual

${ }^{28}$ El Porvenir, 5-12-1850, s. p. En 1862, la reina, de visita en Cádiz, le otorgó la medalla de plata de la exposición por Retrato de una niña. Fue el mismo año en que murió su esposa.

${ }^{29}$ ARABASIHS, fondo Actas, Libro de actas de la sesión de pintura, 1866, $\mathrm{n}^{\circ} 1$.

${ }^{30}$ ARABASIHS, fondo Cartas, Carta 1.215 del Copiador de Oficios n ${ }^{\circ} 3$.

31 ARAPBAC (Archivo de la Real Academia Provincial de Bellas Artes de Cádiz), fondo de Actas, Libro de actas de juntas, 1862-1874, 10-7-1866, p. 154.

32 ARAPBAC, Académicos, Historial de las plazas de Académicos de Número de la Academia Provincial de Bellas Artes de Cádiz, 1940, p. 23.

${ }_{33}$ No fue antes porque, como él mismo declaró, se "hallaba ausente de la ciudad". ¿Podría estar, de nuevo, en Madrid?

${ }^{34}$ Estas obras no resultaron premiadas. YBARRA OSBORNE, Eduardo e YBARRA HIDALGO, Eduardo: Notas sobre José María Ybarra, primer conde de Ybarra. Sevilla, 1984, p. 151. 
Javier Lasso de la Vega ${ }^{35}$. Del año siguiente se conserva un ofrecimiento dirigido al Ayuntamiento hispalense con objeto de adquirir los cuadros que había pintado en 1877 y testimoniando la presencia en Sevilla del rey Alfonso XII ${ }^{36}$.

Ninguna noticia ni referencia aparece ulteriormente en la prensa o en la historiografía sobre Romero, a pesar de que se pensaba podía haber fallecido ese año en Sevilla, o, por el contrario, en Cádiz hacia $1888^{37}$. Sin embargo, conociendo que nuestro pintor había viajado con asiduidad a Madrid -incluso desde los mismos inicios de su carrera-, buscando nuevos mercados para su producción, decidimos, tras no encontrar ningún dato en los registros de los cementerios de Sevilla, Cádiz y Málaga, indagar en los del de la Almudena de la capital, encontrando la siguiente información, que esclarecía tanto el lugar como la fecha exacta de fallecimiento del pintor: "JOSÉ MARÍA ROMERO LÓPEZ inhumado el 09/10/1894 en sepultura temporal, cuartel 37, manzana 19, letra $\mathrm{H}$, cuerpo 6, trasladándose sus restos al Osario Común el día 31/03/1905"38. Murió, por consiguiente, Romero lejos de su tierra natal. Al marchar a Cádiz, quedó la labor de Manuel Ussel de Guimbarda (Trinidad de Cuba, 26 de noviembre de 1833-Cartagena, 9 de mayo de 1907) como retratista de la Sevilla oficial. Algunos de los alumnos que formó o que siguieron sus pasos fueron José Villegas Cordero (1844-1921), José Díaz Varela (1827-1903), José de Vega, Ventura de los Reyes Conradi ${ }^{39}$, Ignacio Verdeja (n. 1820), Rafael García Hispaleto (1833-1854), y Marcos Hiráldez de Acosta (n. c. 1830), lista que tendría que ser completada con los, hasta el momento desconocidos, que pudo formar en Cádiz.

\section{ADICIONES AL CATÁLOGO}

Precisamente es en Cádiz el lugar donde se localizan las obras inéditas que aportamos en el presente estudio al catálogo de José María Romero. En la Casa Generalicia de las Franciscanas del Rebaño de María - orden fundada por la Madre María Encarnación Carrasco Tenorio en 1878, una religiosa que provenía de la compañía de María de la cercana localidad de San Fernando-, sita en la calle Costa Rica $\mathrm{n}^{\circ} 5$ de la capital gaditana, se encuentra el núcleo más importante de pintura religiosa de nuestro pintor. No son cuadros realizados en origen para este colegio privado de enseñanza, que lleva por nombre San Francisco de Asís

${ }^{35}$ Referenciado por VALDIVIESO, Enrique y FERNÁNDEZ LÓPEZ, José: Pintura romántica sevillana..., op. cit., p. 176.

${ }^{36}$ Este dato lo aportaron PÉREZ, J. M.; DEL RÍO, F. y FRANCO, A.: Catálogo de la exposición de la colección de pinturas del Ayuntamiento de Sevilla. Sevilla, 1983, p. 126.

${ }^{37}$ Así se publicó en Pintura del s. XIX “Colección Bellver”. Córdoba, 1997, p. 180.

38 Agradecemos en este punto la servicial ayuda del servicio de administración del Cementerio de Nuestra Señora de la Almudena, Avenida de Daroca, 90, 28017 de Madrid.

${ }^{39}$ El Porvenir, 15-8-1860, s. p. 
y cuyas labores docentes se trasladaron hace algunos años a la calle Trille $n^{\circ} 13$ de la misma ciudad, sino que fueron encargados para el domicilio particular de María Dolores Aguirre Larraondo (Cádiz, 1840-1887), gran benefactora de la comunidad $^{40}$. A finales del pasado siglo presentaban importantes problemas de conservación debidos a la humedad que los afectaba, motivo por el que fueron restaurados y, en algunos casos, repintados, por Francisco Fernández en 2001.

Forman un conjunto de veintinueve piezas, hoy de discurso discontinuo y desigual, en el que predominan los temas evangélicos y, especialmente, los episodios que jalonan la vida de la Virgen. Sin embargo, ante la falta de certeza en las atribuciones de muchas de ellas y por lo patente del proceso restaurador, hemos optado por presentar y analizar las siete pinturas que, o bien se han encontrado firmadas por Romero o que sin dudas responden a su estilo. Probablemente estas obras intentaban ofrecer valores devocionales que funcionaran en el oratorio y domicilio particular de la rica propietaria que los adquirió. La estética que los preside, la más cercana a la sensibilidad burguesa decimonónica, no opera hoy de la misma manera, máxime cuando la colección ha sido trasladada y repartida por distintas estancias, pero, a buen seguro, sirven como marco adecuado en la residencia de las religiosas, a las que ilustran y recuerdan algunos de los episodios veterotestamentarios o evangélicos más destacados para el sostenimiento de la fe católica. Con respecto a la cronología, conocemos que Romero participó en la exposición de Cádiz de 1860 con Seis retratos, Nuestra Señora del Carmen y San Rafael y Tobías $^{41}$. Como dos de los cuadros que se guardan en la Casa Generalicia responden a esta misma temática, podríamos pensar que la señora Aguirre Larraondo los adquirió en esa exposición y, posteriormente, quizá en varios

${ }^{40}$ Era hija de Francisco Javier de Aguirre Bernabé y María del Carmen Larraondo Urruela, ambos naturales de Guatemala y que contrajeron matrimonio en la parroquia de San Antonio de Cádiz en 1834. María de los Dolores Aguirre Larraondo se casó en Cádiz en 1858 con Manuel María Enrique de Ortiz y Urruela, licenciado en Leyes. Esta señora tan distinguida, de generoso corazón, fue bienhechora y protectora del Instituto de Franciscanas del Rebaño de María desde sus comienzos, al cual le unían fuertes lazos por ser confesada del cofundador, padre Francisco de Asís Medina y Muñoz, quien también era capellán de su oratorio privado. En su testamento dejaba para el instituto todos sus bienes muebles e inmuebles, y una casa para el asilo, que ella deseaba fuese la llamada Casa de las Columnas, ubicada en la calle Juan de Andas, y que, debido a la pérdida de un pleito entablado por los albaceas testamentarios, de forma ajena a la voluntad de la donante, no pudo utilizarse, adquiriéndose en su lugar el mencionado inmueble de la calle San Sebastián, hoy Costa Rica. Toda esta información proviene del archivo del colegio y nos ha sido facilitada por la hermana Rosario Raigón Córdoba, a quien agradecemos su notable ayuda.

${ }^{41}$ El Porvenir, 10-10-1860, s. p. De esa noticia se desprende que Romero veraneaba en Cádiz, algo que prueba que ya había alcanzado una notable consideración económica. 
años, encargara a Romero el resto, sobre todo coincidiendo con las fechas de su residencia en la ciudad gaditana a partir de 1867.

Pasando al análisis de las obras, colgado sobre el muro de una de las esquinas del patio de la casa se halla el óleo sobre lienzo Moisés bebiendo del pozo de Madián acompañado por las hijas de Jetró (Figura 1). Sus dimensiones son $100 \mathrm{~cm}$ de alto y 80 de ancho y reproduce un instante del episodio narrado en el libro del Éxodo 2, 15-18: "Moisés huyó del Faraón y se detuvo en la tierra de Madián, sentándose junto a un pozo. El sacerdote de Madián tenía siete hijas. Vinieron estas a sacar agua, y cuando estaban llenando los abrevaderos para dar de beber al rebaño de su padre, llegaron unos pastores y las echaron de allí. Entonces Moisés se levantó, salió en defensa de las jóvenes y abrevó su rebaño". La composición está resuelta sobre un fondo de paisaje de atmósfera nublada y completado por edificios percibidos en lontananza. Palmeras y otros árboles se disponen tanto a la izquierda como a la derecha para encuadrar los dos grupos de personajes representados. En el centro de la escena un joven Moisés, ataviado con turbante y vestido con túnica corta verde y mantolín rojo, se ciñe un fajín de tejido adamascado y lleva una bolsa con correa colgada sobre su hombro derecho. Se encuentra bebiendo del recipiente que le tiende Séfora, que se convertirá posteriormente en su esposa, ataviada aquí con ropajes elegantes y apartando con decoro su rostro del de Moisés. Los dos personajes ocultan parcialmente el pozo de Madián. El resto de figuras, todas femeninas, superan en número las siete hijas de Jetró que menciona la Escritura, pero Romero las pinta tratando de otorgarles una impronta diferente a cada una, ya sea por medio de las prendas de ropa, sea por la forma de recoger sus cabellos o por la disposición de su cuerpo: unas se apoyan sobre el pozo, otras, de rodillas, comparten el agua volcando sus recipientes sobre otros vacíos. Los colores utilizados son bastante fríos, algo frecuente en este pintor. Las encarnaciones de los personajes son muy pálidas, mientras que el fondo de paisaje y la vegetación aparecen más oscuros y densos, algo que contrasta, por ejemplo, con el albor que desprende el pilar coronado por esfera que ocupa un lugar preeminente en la composición.

En otra estancia del inmueble, concretamente en el recibidor, se halla la pintura Tobías y el Ángel (Figura 2), de $107 \mathrm{~cm}$ de alto y 85 de ancho. Este óleo sobre lienzo lleva la firma de José María Romero en el ángulo inferior derecho y, como señalábamos con anterioridad, puede ser el que presentó el artista a la exposición de 1860. La fuente empleada es el libro de Tobías 6, 1-9: "El joven y el ángel partieron. Y el perro se fue con ellos. Caminaron hasta el anochecer. Pasaron la noche a la orilla del río Tigris. Tobías bajó al río a lavarse los pies. Un pez enorme saltó del agua y quería devorarle el pie. Tobías gritó. El ángel le dijo: «Agarra al pez y no lo dejes escapar». Tobías lo agarró y lo sacó a tierra". Romero consigue aquí una muy buena interpretación del ángel e incluye el perro que referencia la Escritura. Sin embargo, el fondo aparece muy oscurecido. Es una obra concebida con gran sencillez, en la que se prescinde de detalles accesorios y se colocan las 
figuras en primer plano con objeto de focalizar adecuadamente la historia representada.

El lienzo más importante de toda la serie es Jesús curando a los ciegos de Jericó (Figura 3), de $106 \mathrm{~cm}$ de alto y 185 de ancho. Firmado en el ángulo inferior izquierdo, también está expuesto en el recibidor. La fuente de la pintura se halla en el Evangelio de Mateo 20, 29-34: "Al salir de Jericó, los siguió mucha gente. Dos ciegos, sentados junto al camino, oyeron que pasaba Jesús, y gritaron: «¡Señor, hijo de David, ten compasión de nosotros!». La gente los reprendió para que se callasen, pero ellos gritaban con más fuerza: «iSeñor, hijo de David, ten compasión de nosotros!». Jesús se detuvo, los llamó y les dijo: «¿Qué queréis que os haga?». Le dijeron: «iSeñor, que se abran nuestros ojos!». Jesús se compadeció, tocó sus ojos, y al punto recobraron la vista y se fueron tras él"42. Posiblemente posterior a la anterior en cronología de realización, esta pintura muestra la madurez de Romero al dejar un tanto de lado el eco murillista. Ahora obvia sus usuales tonos cálidos e incorpora toda la gama de azules. En el centro de la composición aparece Cristo imponiendo sus manos a uno de los ciegos, arrodillado, mientras que otro, en idéntica postura espera su turno. A la izquierda observan la escena varias mujeres con sus niños en brazos. A la derecha una arquitectura semiderruida - quizá un arco de triunfo-, permite la entrada de varios personajes que comentan entre ellos lo que acontece. Al fondo, muy bien dibujado, se observa un paisaje urbano con casas y palmeras.

Volviendo al patio de la Casa Generalicia encontramos La Resurrección de Lázaro (Figura 4), que representa la escena referida en el Evangelio de Juan 11, 38-44: "Jesús se estremeció profundamente otra vez al llegar al sepulcro, que era una cueva con una gran piedra puesta. Jesús dijo: «Quitad la piedra». Marta, la hermana del difunto, le dijo: «Señor, ya huele, pues lleva cuatro días». Jesús le respondió: «¿No te he dicho que, si crees, verás la gloria de Dios?». Entonces quitaron la piedra. Jesús levantó los ojos al cielo y dijo: «Padre, te doy gracias porque me has escuchado. Yo bien sabía que siempre me escuchas; pero lo he dicho por la gente que me rodea, para que crean que tú me has enviado». Y dicho esto, gritó muy fuerte: «¡Lázaro, sal fuera!». Y el muerto salió atado de pies y manos con vendas, y envuelta la cara en un sudario. Jesús les dijo: "Desatadlo y dejadlo andar»". Mide $100 \mathrm{~cm}$ de alto y 80 de ancho y está realizado con la misma técnica que los lienzos anteriormente reseñados. Lo mejor de esta composición descansa sobre las diferencias plásticas: a partir de un intenso claroscuro -el espacio donde se encuentran los personajes no es apreciable, salvo las escalinatas que descienden a la tumba de Lázaro, debido al ambiente opaco que lo preside todo, pero las figuras están perfectamente iluminadas-, se diferencian dos planos. Ambos están ocupados por grupos de personajes: el superior, regido por Cristo, representado

${ }^{42}$ Solo Mateo menciona dos ciegos. Por contra, Marcos, Lucas y Juan solo mencionan uno en Jericó en las fechas próximas a la Pasión y Muerte. 
con preponderante altura y rodeado por apóstoles, discípulos y otros figurantes entre los que se diferencia a Pedro, Juan y a las hermanas del recién resucitado, Marta y María; el inferior, formado por el círculo de incrédulos que se arraciman alrededor del sorprendido Lázaro y desatan su sudario. Entre uno y otro se disponen casi en paralelo más personajes gesticulantes por obra del milagro sucedido, con amplitud de aspavientos y expresiones. Una vez más, Romero vuelve a recurrir a su destreza para la captación de los detalles anecdóticos: los niños colocados en el centro de la composición que se asustan por lo que acaban de presenciar, el hombre que se acerca gateando al resucitado para tocarlo, los exquisitos ropajes de Marta o la gracilidad de los pliegues de las túnicas y mantos. Todo está resuelto con efectividad, pero como es habitual en la obra de Romero, se aprecian indicios de distancia y desapego con las emociones más profundas.

En el mismo espacio se localiza La unción en Betania (Figura 5), igualmente de $100 \mathrm{~cm}$ de alto y 80 de ancho y realizado con la misma técnica que los demás. Se representa en él la ocasión recogida en el Evangelio de Lucas 7, 36-45: "Un fariseo invitó a Jesús a comer con él. Jesús fue a su casa y se puso a la mesa. Había en la ciudad una mujer pecadora, la cual, al enterarse de que Jesús estaba a la mesa en casa del fariseo, se presentó allí con un vaso de alabastro lleno de perfume, se puso detrás de él a sus pies, y, llorando, comenzó a regarlos con sus lágrimas y a enjugarlos con los cabellos de su cabeza, los besaba y ungía con el perfume. El fariseo que le había invitado, al verlo, se decía: «Si este fuera profeta, conocería quién y qué clase de mujer es la que lo toca. ¡Una pecadora!»”. También está añadida la inclusión de Marta y Judas, siguiendo en algún aspecto el relato de Juan 12, 1-8, que fija este episodio en Betania seis días antes de la fiesta de la Pascua. La obra está resuelta con solvencia a partir de una composición sencilla, pero efectiva. El numeroso grupo de personajes ocupa todo el lienzo, pero se hallan en el centro de un espacio abierto entre dos edificios de impronta clasicista: del de la izquierda solo se aprecia parte de una columnata adintelada que sostiene un balcón abalaustrado; del otro el extremo de una fachada de dos plantas: la baja con vanos con frontones triangulares entre pilastras de orden corintio, la alta con vanos cuadrados libres de decoración. Al fondo se estiman otros edificios del mismo tipo y un cielo borrascoso y anochecido. Las figuras se distribuyen a ambos lados de un larga mesa - colocada de perfil y sobre la que se aprecian algunas viandas y bebidas-, habiendo optado Romero por caracterizar con mucho mayor detalle los más cercanos e importantes y por dejar simplemente bosquejado los que están al otro lado de la mesa -el grupo de invitados- y que sirven únicamente para completar la composición. En el conjunto principal destacan Cristo sentado -Romero ha tomado aquí el modelo utilizado por Murillo en La multiplicación de los panes y los peces (1669-1670), de la iglesia del Hospital de la Caridad, ataviándolo con una túnica y manto de diferentes tonalidades azuladas-; y María, la hermana de Marta y Lázaro, impregnando con el perfume su pie derecho. Alrededor del misterio de la unción se reconoce a Simón 
el Leproso -también llamado El Fariseo en otros escritos evangélicos- ${ }^{43}$, abrigado con armiño y tocado con turbante; a Marta, que se inclina hacia el rostro de Cristo; a Judas, turbulento detrás de Cristo; a Lázaro, de pie entre Simón y Marta, con gesto apacible y sosteniendo una copa; e incluso al discípulo que, a la izquierda del cuadro y con gesto apremiante, exige que un sirviente vierta vino en su ponchera, el mismo que en la pintura anterior se acercaba a Lázaro resucitado para tocarlo. La obra ofrece detalles curiosos, tan ensayados por Romero en otras composiciones, y tan del gusto de los comitentes: el perrillo que lame algún trozo de comida caído sobre el pavimento embaldosado o el muchacho del extremo inferior izquierdo que se encarga de proveer la mesa de jarras de distinto formato y material. Además de eso, la doncella que sostiene lo que parece un pastel de dos pisos rematado por flores y el repertorio de gestos de los discípulos e invitados al banquete del episodio evangélico, pero representado en un ambiente anacrónico y de refinado lujo.

El Mensaje de la Resurrección tiene idénticas medidas y técnica empleada que el anterior (Figura 6). El suceso está registrado en el Evangelio de Mateo 28, 1-7: "Pasado el sábado, al rayar el alba, el primer día de la semana, fueron María Magdalena y la otra María a ver el sepulcro. De pronto hubo un gran terremoto, pues un ángel del Señor bajó del cielo, se acercó, hizo rodar la losa del sepulcro y se sentó sobre ella. Su aspecto era como un rayo, y su vestido blanco como la nieve. Los guardias temblaron de miedo y se quedaron como muertos". Este es uno de los cuadros más conseguidos de Romero, en primer lugar por los colores utilizados, más cálidos, impregnados desde el centro del nuboso rompimiento de gloria del que ha emanado el ángel hasta la oscuridad de los extremos del sepulcro. En segundo lugar por la contrastada apariencia de las figuras: gráciles y delicadas el ángel, la Virgen y las Tres Marías, rudas y toscas las de los soldados romanos que se despiertan sobresaltados y hacen ademán de huir con pavor. Romero no ha ubicado aquí al emisario sentado sobre el sepulcro, como dice la Escritura, sino graciosamente sobre una masa nublosa que cae en cascada o que se adapta a su contorno. Del sepulcro -sobre el que sobresale un extremo del santo sudario-, se aprecia una esquina, decorada con un balaustre. La Magdalena, arrodillada junto a la piedra, vuelve a presentar reminiscencias murillistas, quizá de la Magdalena penitente ejecutada por el maestro barroco entre 16501655, conservada actualmente en el Virginia Museum of Fine Arts de Richmond. Las otras figuras femeninas son más convencionales y anodinas.

En el último cuadro se figura el Descubrimiento de la cruz por Santa Elena (Figura 7). Con la misma técnica y dimensiones que los anteriores, personaliza

${ }^{43}$ Claude-Joseph Drioux (1820-1898) quiso solucionar la confusión que ofrecen las fuentes evangélicas identificando a Simón el Leproso como el padre de los hermanos Lázaro, Marta y María. Vid. ABBÉ DRIOUX: La Bible Populaire. Histoire illustrée de l'Ancien et du Nouveau Testament. T. 2. París, 1864, p. 119. 
el suceso que protagonizó Santa Elena (Drepanum, c. 250-Roma, c. 330), madre del emperador Constantino I (Naissus, c. 272-Nicomedia, 337), quien, gracias al Edicto de Milán, permitiría la tolerancia religiosa dentro de las fronteras imperiales y las peregrinaciones a los Santos Lugares para recopilar aquellas reliquias que atestiguaran el paso temporal de Cristo y de los apóstoles por Tierra Santa. Flavia Julia Elena Augusta, puesto que este fue su nombre antes de la santidad, fue de las primeras en visitar aquellos enclaves, fundando instituciones religiosas y recogiendo objetos del pasado que tuvieran especial significación para el culto cristiano ${ }^{44}$. Fuentes diversas, como las debidas a San Ambrosio y Eusebio de Cesarea -también otras de menor importancia-, ofrecen el suceso que la pintura de Romero refiere: gracias a una visión en la que se le informaba sobre cuál era el recinto que había de mandar excavar, la madre del emperador, dispuso todo y pudo encontrar tres cruces enterradas bajo un monumento erigido a Venus. A pesar de que sobre una de ellas estaba colocado el INRI que mandó Pilato para señalar el martirio de Jesús Nazareno, el obispo de Jerusalén, Macario, quiso comprobar la autenticidad de la reliquia aproximando los tres maderos a una mujer moribunda. Al principio, cuando las dos primeras piezas tocaron el cuerpo de la enferma, esta no sintió ninguna mejoría, pero cuando se hizo lo mismo con la tercera recobró inmediatamente la salud. A diferencia de las otras dos cruces, en las que probablemente murieron Dimas y Gestas, la tercera era el verdadero Lignum Crucis. Para conmemorar ese hecho, Elena mandó erigir en aquel lugar del Calvario la basílica del Santo Sepulcro ${ }^{45}$. En esta ocasión, Romero desestabiliza la composición tanto en número de personajes como en iluminación: el lado izquierdo, por donde un sirviente se lleva una de las cruces inservibles, está oscurecido y menos detallado. En el centro se erige la Vera Cruz junto a la mujer moribunda, caracterizada por nuestro artista como una joven pálida vestida de blanco de la que irradia luz y lozanía. A su lado y de rodillas, fácilmente identificable por su atuendo regio y su corona, se coloca Santa Elena, que, con gesto de oración se maravilla del descubrimiento. Detrás, y con mayor expresividad, se sitúa el obispo Macario y tras ellos una serie de figurantes que completan la escena que tiene lugar en el interior de un gran edificio de arquitectura clasicista y enlosado de decoración geométrica.

Con la aportación de estas pinturas pretendemos continuar ahondando en la comprensión de la obra de José María Romero, el perfecto traductor del

${ }^{44}$ Probablemente fue acompañada por Luciano de Antioquía. El ejemplo de Santa Elena sirvió para las posteriores incursiones en Jerusalén y Belén de personalidades como Santa Paula, Fabiola, Marcela y Melania. Vid. CAMERON, A.: El Mundo Mediterráneo en la Antigüedad Tardía. Barcelona, 1998, p. 81.

${ }^{45}$ Toda la historia está referida y analizada en LARA MARTÍNEZ, María y LARA MARTÍNEZ, Laura: "Santa Elena y el hallazgo de La Cruz de Cristo", Revista Comunicación y Hombre, 3, 2007, p. 45. 
murillismo decimonónico, que tomaba modelos de referencia, pero aportaba grandes dosis de detallismo en la personificación de las figuras, sobre todo en sus atuendos y expresiones, y elaboraba composiciones mucho más rígidas que las del pintor barroco. Los colores, de una gama bastante más fría que la empleada por Murillo, ya que nunca aparecen tonos estridentes, y el dibujo, mucho más riguroso, se completa con una pincelada notablemente compacta. Algo muy interesante y sobre lo que habrá que seguir estudiando es el hecho de que Romero nunca se presentara a las exposiciones nacionales de Bellas Artes, inauguradas por Isabel II en 1856. Quizá prefirió limitarse a los círculos de las ciudades más cercanas a él, donde ya su personalidad era de sobra conocida. Una personalidad que fluctuaba entre el rigor academicista de Esquivel y la espontaneidad de Gutiérrez de la Vega.

Fecha de recepción: 29 de octubre de 2017

Fecha de aceptación: 12 de abril de 2018 


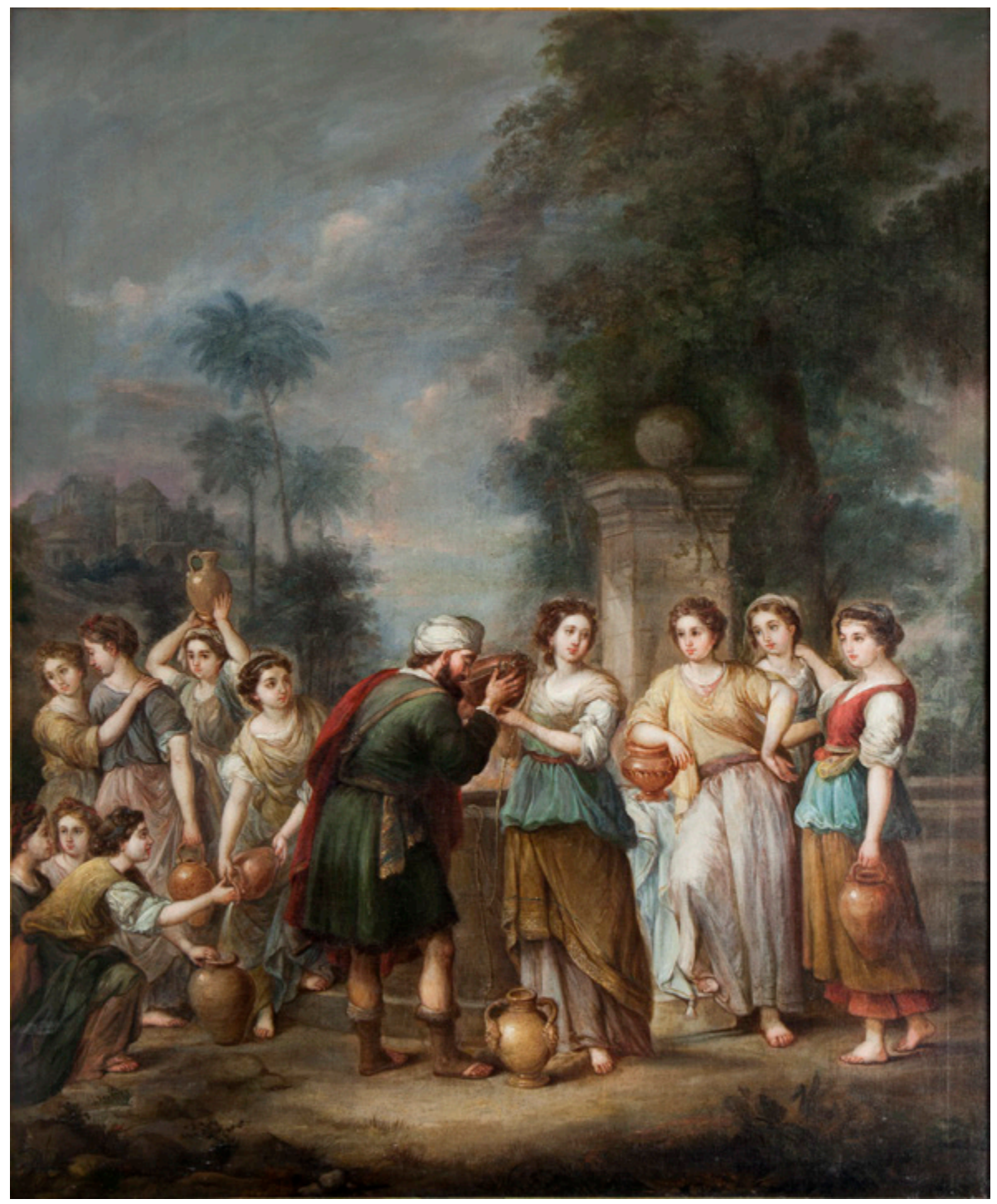

Figura 1. José María Romero, Moisés bebiendo del pozo de Madián acompañado por las hijas de Jetró, 1860-1879, Casa Generalicia de las Franciscanas del Rebaño de María, Cádiz. 


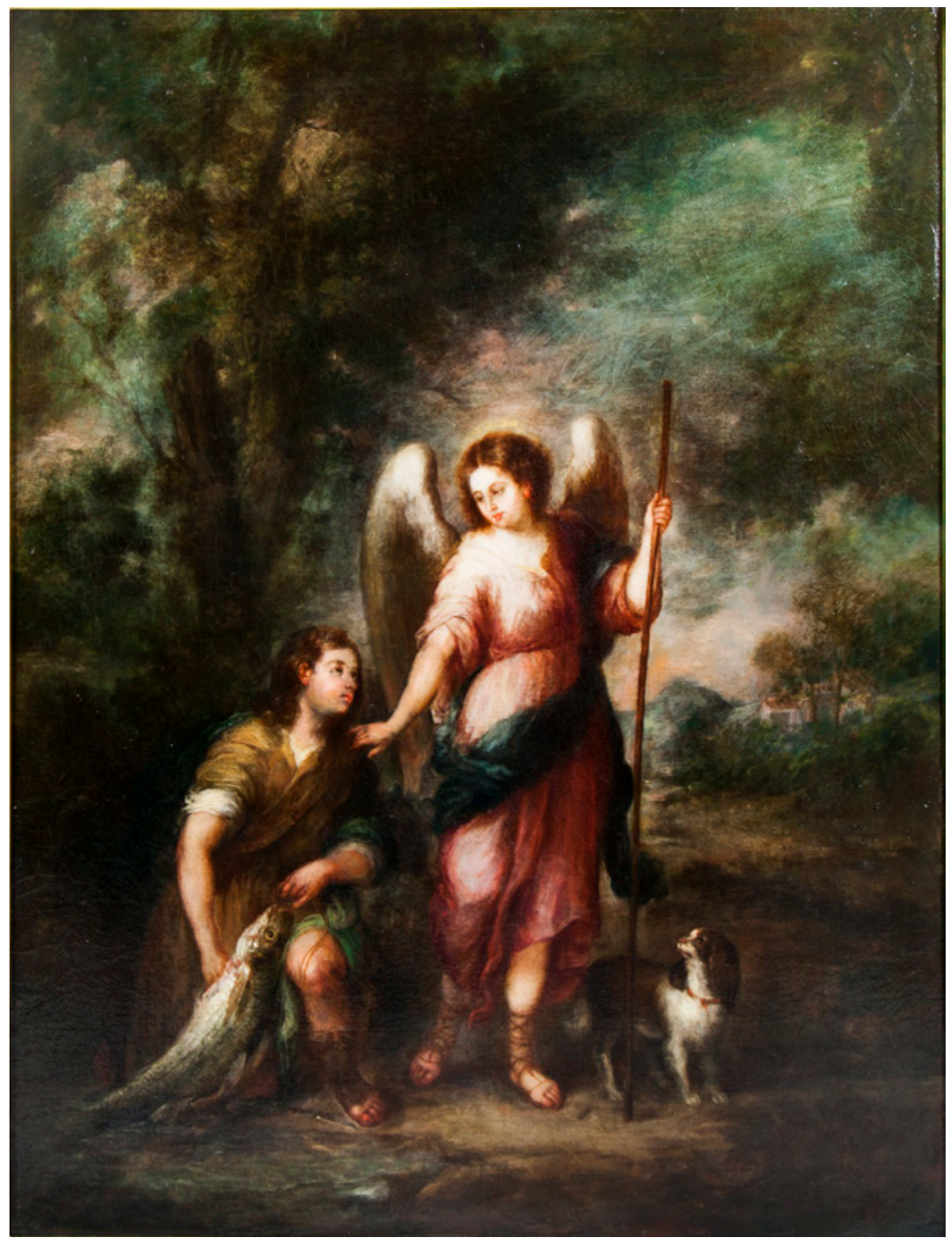

Figura 2. José María Romero, Tobías y el Ángel, 1860-1879, Casa Generalicia de las Franciscanas del Rebaño de María, Cádiz. 


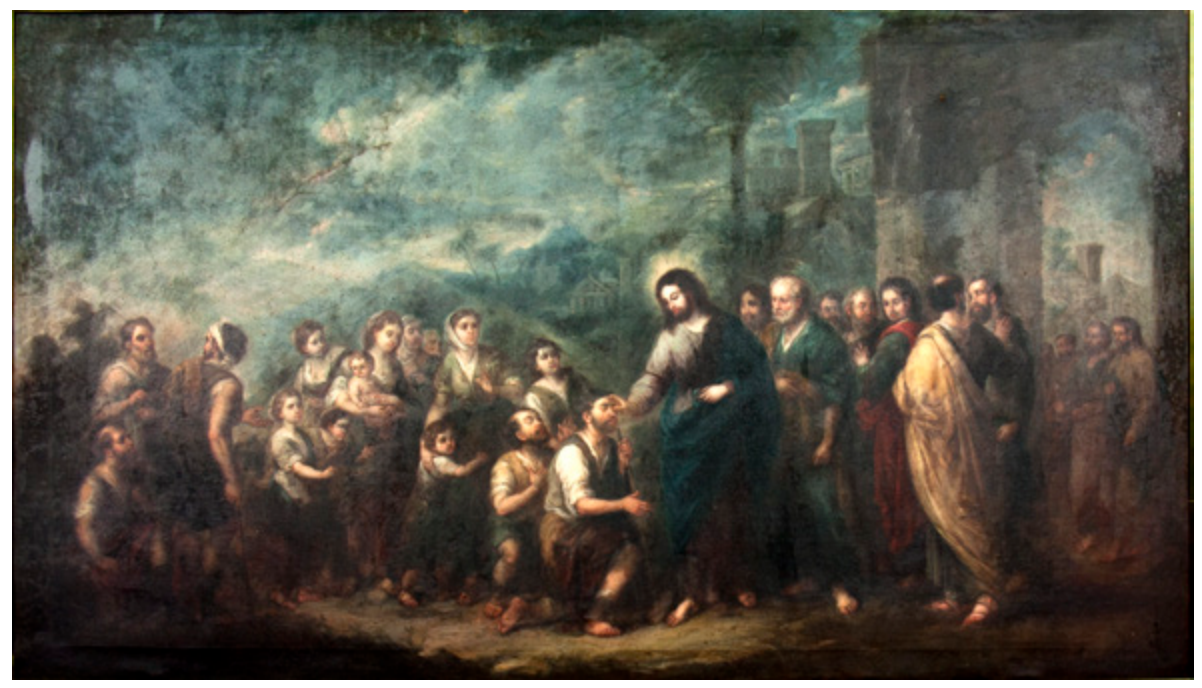

Figura 3. José María Romero, Jesús curando a los ciegos de Jericó, 1860-1879, Casa Generalicia de las Franciscanas del Rebaño de María, Cádiz. 


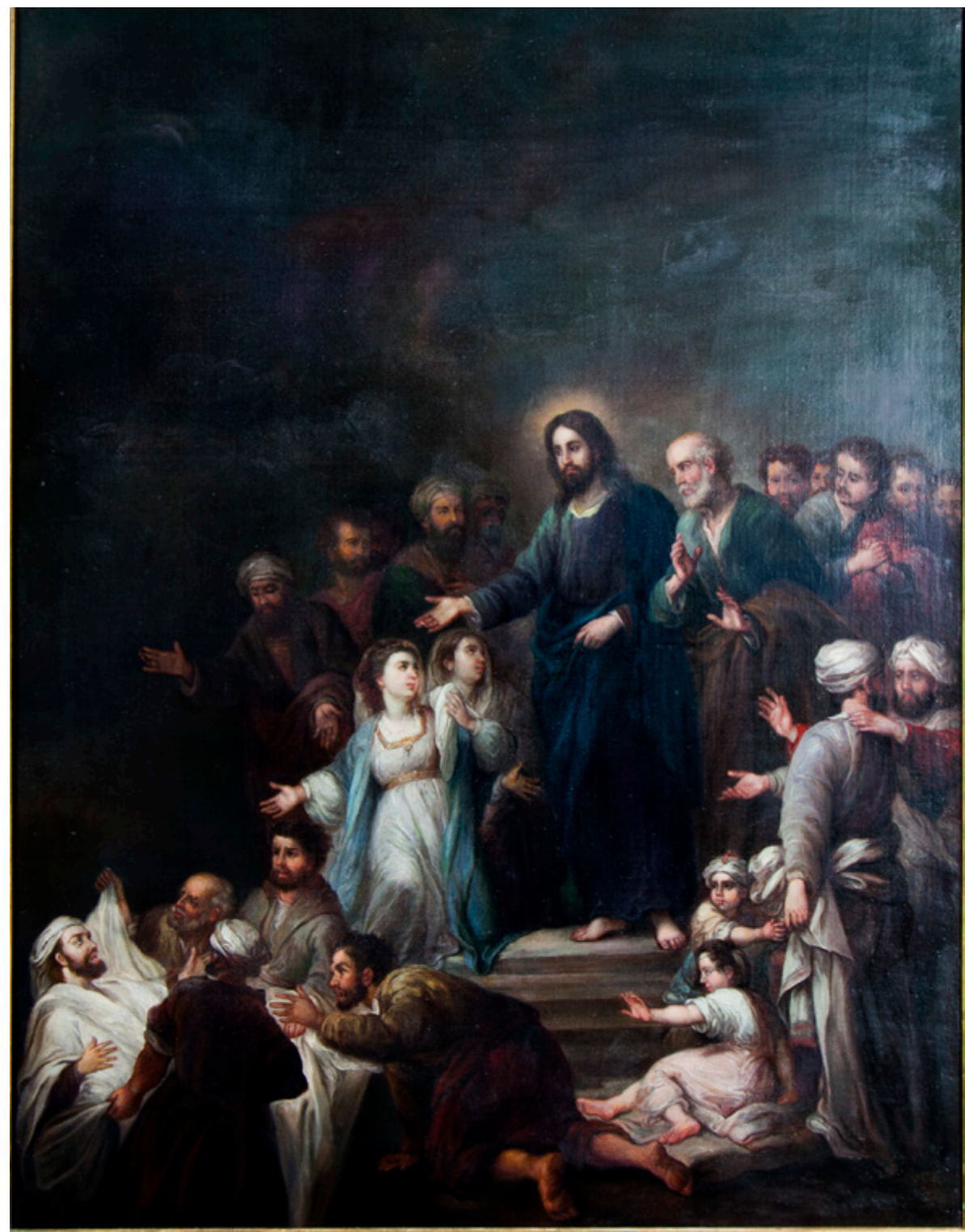

Figura 4. José María Romero, Resurrección de Lázaro, 1860-1879, Casa Generalicia de las Franciscanas del Rebaño de María, Cádiz. 


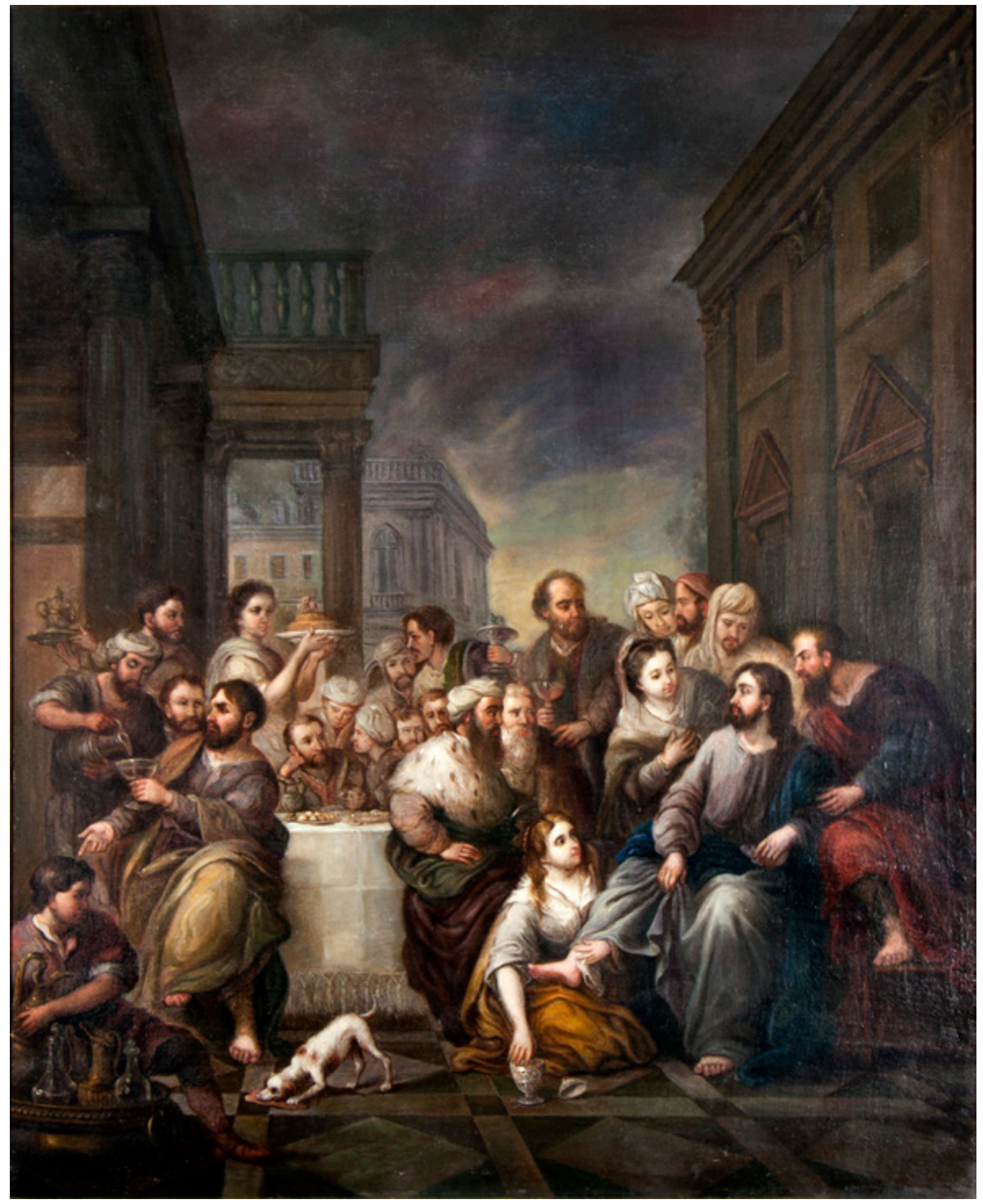

Figura 5. José María Romero, La unción en Betania, 1860-1879, Casa Generalicia de las Franciscanas del Rebaño de María, Cádiz. 


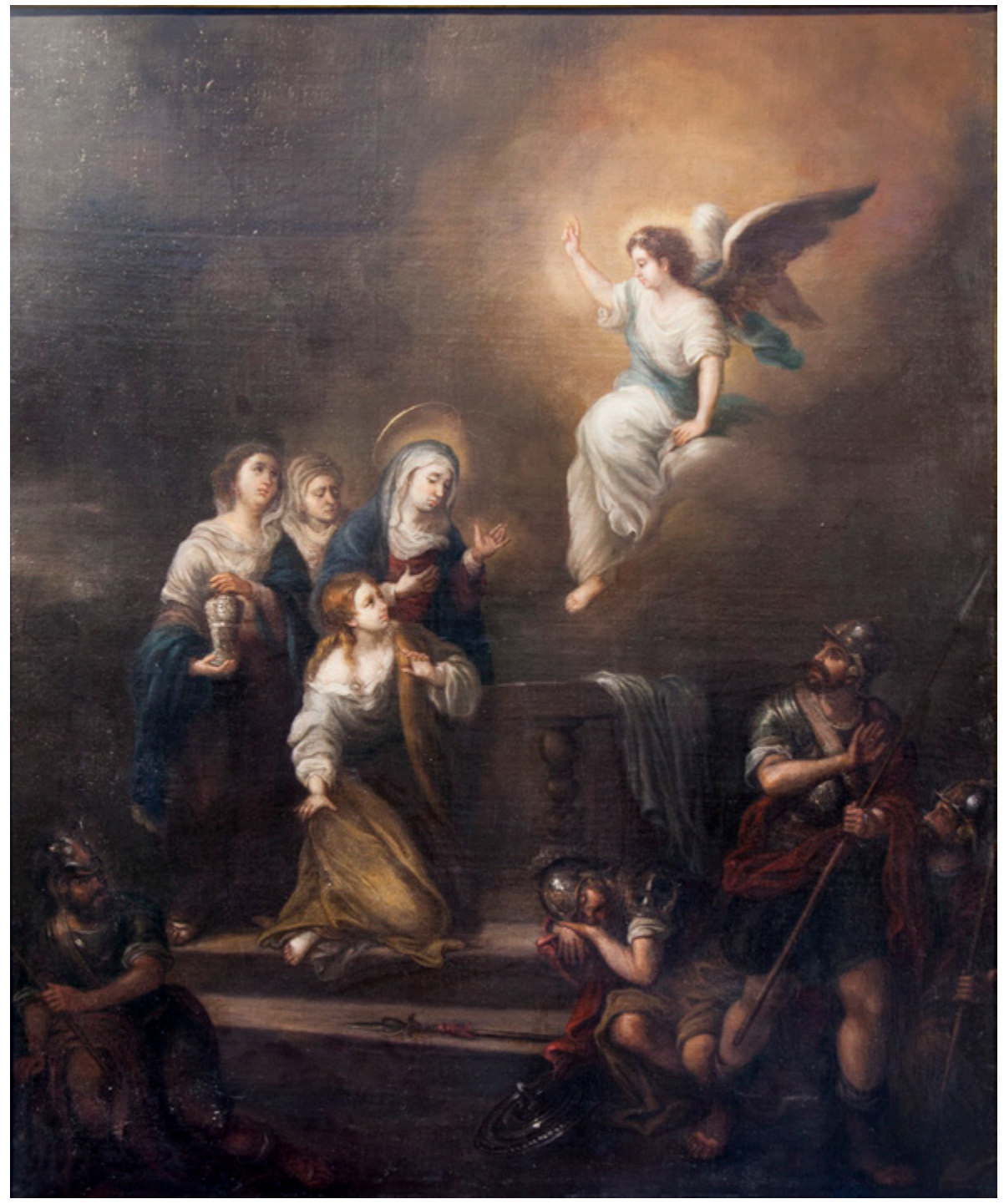

Figura 6. José María Romero, Mensaje de la Resurrección, 1860-1879, Casa Generalicia de las Franciscanas del Rebaño de María, Cádiz. 


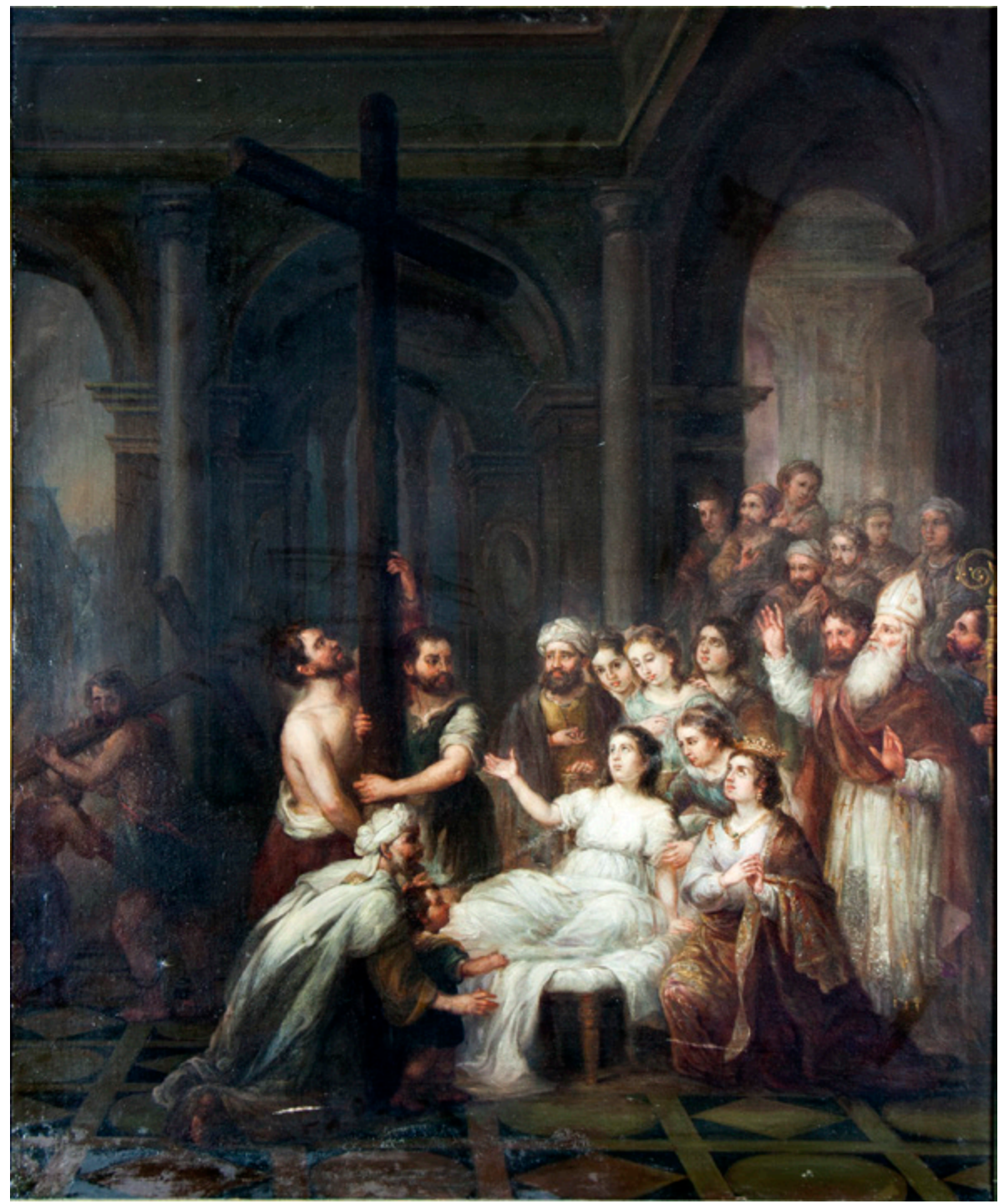

Figura 7. José María Romero, Descubrimiento de la cruz por Santa Elena, 1860-1879, Casa Generalicia de las Franciscanas del Rebaño de María, Cádiz. 